poster prompts can be used to serve as a point of reference. ESS should routinely be incorporated into departmental induction and education.

\section{P28 COMPARISON OF ANXIETY AND DEPRESSION SCORES BETWEEN 2-WEEK WAIT AND BARRETT'S SURVEILLANCE ENDOSCOPY REFERRALS}

Alexander Ho*, Paul Wolfson, Ashley Wilson, Áine Hogan, Hazel McBain, Margaret Duku, Vanessa Ward, Timothy Stone, Sarmed Sami, Laurence B Lovat. Division of Surgery and Interventional Science, University College London, London, UK

\subsection{6/gutjnl-2020-bsgcampus. 103}

Introduction BSG guidelines recommend endoscopic surveillance for patients with Barrett's oesophagus (BE), due to the $0.5 \%$ annual risk of developing oesophageal adenocarcinoma. ${ }^{1}$ Approximately $10 \%$ of GP 2 -week wait (2WW) referrals result in a cancer diagnosis, and patients on a $2 \mathrm{WW}$ pathway should be told of a theoretical risk of cancer. ${ }^{2}$ We therefore performed a case-control study, comparing outpatients referred to endoscopy for BE surveillance (BES) and GP 2WW referrals, to ascertain the effect of possible cancer on patients' anxiety and depression under 2 different scenarios.

Methods Patients were recruited as part of the Saliva to Predict Disease Risk (SPIT) study. This is a multicentre study to improve non-invasive prediction of the risk of $\mathrm{BE}$ and oesophageal cancer. Ethical approval was gained from the Coventry and Warwickshire Regional Ethics Committee (17/WM/ 0079). Anxiety and depression was measured using the Hospital Anxiety and Depression Scale (HADS) questionnaire; this was completed at recruitment in the endoscopy department. ${ }^{3}$ This is a validated tool consisting of 14 questions, scored from 0 to 3 , with 7 questions assigned to each domain. Ordinal logistic regression analysis was performed using $\mathrm{R}$ software v3.6.1 to account for the effect of age and gender on HADS. Results 940 patients, split between 363 BES referrals and 577 $2 \mathrm{WW}$ referrals were included in the final analysis. Median age was 69 for BES and 66 for NBS $(\mathrm{p}=0.002)$. 54\% of patients were female in the $2 \mathrm{WW}$ group compared to $24 \%$ in the BES group $(\mathrm{p}<0.001)$. Accounting for both age and gender, mean HADS anxiety score was 4.76 for BES and 6.61 for $2 \mathrm{WW}$ $(\mathrm{p}<0.001, \quad \mathrm{OR}=1.76 ; 95 \% \mathrm{CI}: 1.38-2.24)$. Mean HADS depression score was 3.57 for BES and 4.60 for $2 \mathrm{WW}$ $(\mathrm{p}<0.001, \quad \mathrm{OR}=1.51 ; \quad 95 \% \mathrm{CI}: \quad 1.19-1.92)$. Interestingly, reduced age and female gender was associated with higher anxiety scores $(p<0.001$ for both), but not depression $(p=n s)$. Conclusions These results suggest that $2 \mathrm{WW}$ patients undergoing endoscopy have higher baseline anxiety and depression than BES patients. Most patients on a BES list would have had at least one previous endoscopy, and may have developed expectations and adaptive mechanisms to their procedure. A previous study found a reduction in depression but not anxiety scores in patients with $\mathrm{BE}$ and non-specific symptoms undergoing OGD. ${ }^{4}$ Our study partially concurs with this; it may be that $2 \mathrm{WW}$ patients have an additional element of anxiety compared to a cohort with non-specific symptoms, which will need further clarification.

\section{REFERENCES}

1. Fitzgerald, R. et al. Gut 63, 7-42 (2014).

2. Cummings, R. et al. BJGP 60, 689-690 (2010).

3. Zigmond, A. et al. Acta Psychiatr. Scand. 67, 361-370 (1983).

4. Essink-Bot, M. et al. Qual. Life Res. 16, 1309-1318 (2007).

\section{P29 ENDOSCOPIC SUBMUCOSAL DISSECTION (ESD) IN THE WESTERN SETTING - IS TUNNELING TECHNIQUE THE WAY FORWARD?}

Ejaz Hossain*, Pradeep Bhandari. Portsmouth Hospital Nhs Trust, West Byfleet, UK

\subsection{6/gutjnl-2020-bsgcampus. 104}

Introduction Since the advent of Peroral Endoscopic Myotomy (POEMS), tunneling technique has become a popular way of performing ESD.

After initial distal dissection, proximal end of the lesion is approached,creating a submucosal tunnel. The tunnel wall is then collapsed to remove the lesion. Data from a tertiary referral centre is depicted in table 1 , demonstrating tunneling technique is a safe, effective and efficient way to perform ESD, specially in Western settings.

\begin{tabular}{llllll} 
Abstract P29 Table 1 & & & \\
\hline & $\begin{array}{l}\text { Average size } \\
\text { (cm square) }\end{array}$ & $\begin{array}{l}\text { Mean } \\
\text { duration }(\mathrm{min})\end{array}$ & $\begin{array}{l}\text { En- bloc } \\
\text { resection }\end{array}$ & Complications \\
\hline $\begin{array}{l}\text { Oesophageal } \\
(\mathrm{N}=15)\end{array}$ & 17 & 99 & $100 \%$ & Bleeding- 0 & Perforation- 0 \\
$\begin{array}{l}\text { Colorectal } \\
(\mathrm{N}=9)\end{array}$ & 36 & 221 & $100 \%$ & Bleeding- 0 & Perforation- 0 \\
\hline
\end{tabular}

\section{P30 SERRATED POLYP DETECTION RATE IN BOWEL CANCER SCREENING COLONOSCOPY VARIES FOUR FOLD BETWEEN COLONOSCOPISTS}

Hein Htet*, Ms Jane Homer, Pete Basford. St Richard's Hospital, Chichester, UK

\subsection{6/gutjnl-2020-bsgcampus. 105}

Introduction Sessile serrated lesions (SSLs) are precursors for $15-30 \%$ of colorectal cancers. SSLs are more subtle and difficult to detect than conventional adenomas. We aimed to analyse factors associated with clinically relevant serrated polyp detection in the UK bowel cancer screening population.

Methods Detailed analysis of the results of 1333 BCSP colonoscopies was performed. Age, gender, FIT vs. Guiac FOBT, endoscope definition (standard definition vs. high definition), screening vs. surveillance procedure and endoscopist were evaluated in relation to serrated polyp detection rate (SPDR), adenoma detection rate (ADR), proximal adenoma detection rate (ProxADR) and advanced ADR (AdvADR). SPDR was defined as percentage of cases with any serrated polyps proximal to the sigmoid colon or serrated polyps $\geq 5 \mathrm{~mm}$ in the rectum or sigmoid colon. SPSS was used for statistical analysis.

Results Of 1333 colonoscopies, 119 were excluded (incomplete data, previous colectomy, site check, bowel scope colonoscopies). Overall SPDR was $16.1 \%$ (range by endoscopist 7.6 - 31.9\%). Overall ADR was 59.12\% (range by endoscopist $52.3-72 \%$ ), ProxADR $35.4 \%$ (range by endoscopist 25.4 - 52.2\%) and AdvADR 25.6\% (range by endoscopist 19.7 31.9). SPDR was significantly associated with endoscopist ( $p$ $<0.001$ ), but was not associated with age, gender, FIT vs Guiac FOBT, screening vs surveillance procedure or endoscope definition. Mean significant serrated polyps per procedure was 0.254 (range by endoscopist 0.137 - 0.637). ADR was 